\title{
Detection and Analysis of Pseudorabies Virus gI antibody in an Extensive Pig Farm from 2015 to 2018
}

\author{
Jintao Wang ${ }^{1}$, Huansheng Han ${ }^{1}$, Jiasan Zheng ${ }^{1}$, Chunqiu Li $^{1}$, Wanning Liu ${ }^{1}$, and Dongbo \\ Sun $^{1}$ \\ ${ }^{1}$ Heilongjiang Bayi Agricultural University
}

May 20, 2020

\begin{abstract}
$\mathrm{PR}$ is an endemic disease in most regions of China, but the report about the dynamics of PRV gI antibody in one farm was rarely. In order to analyze the dynamics of PRV gI antibody in one farm, 1513 serums from the different pigs in a farm were collected to detect the gI antibody by ELISA. The results in July 2015 indicated only the gilts were PRV gI antibody positive, and the other pigs were all PRV gI antibody negative. But the brain PRV gE gene from 10 piglets were almost positive, their PRV gI antibody were all negative. The results from October 2015 to July 2018 indicated that in the boar herd, 3 positive individuals were found in October 2015 and subsequently they were culled. In the following tests, the boar herd always kept the negative state. The positive rate in the sow herd was always more than $70 \%$ from October 2015 to October 2017. In January 2018, the positive rate decreased to $27 \%$, but it was up to $40 \%$ and $52 \%$ in April and July 2018. For 100-day pigs, the positive rate obviously decreased in October 2016 and then always kept less than 30\% in the later detection. For 150-day pigs, the positive rate obviously decreased to $16 \%$ in January 2017 and transferred to the negative in July 2017. The positive trends from the 40-day pig to the 150-day pig were all remarkably decreased in three tests in 2018. These results indicate that the serological detection is not appropriate in the early stage of the PRV infection, and the introduction of gilts is a risk factor for a PRV-negative farm. The dynamic data of the PRV gI antibody provide the reference for the farm that want to carry out the PR eradication program.
\end{abstract}

\section{Hosted file}

Detection and Analysis of PRV gI antibody in a Intensive Pig Farm from 2015 to 2018. doc available at https://authorea.com/users/324578/articles/452738-detection-and-analysis-ofpseudorabies-virus-gi-antibody-in-an-extensive-pig-farm-from-2015-to-2018 


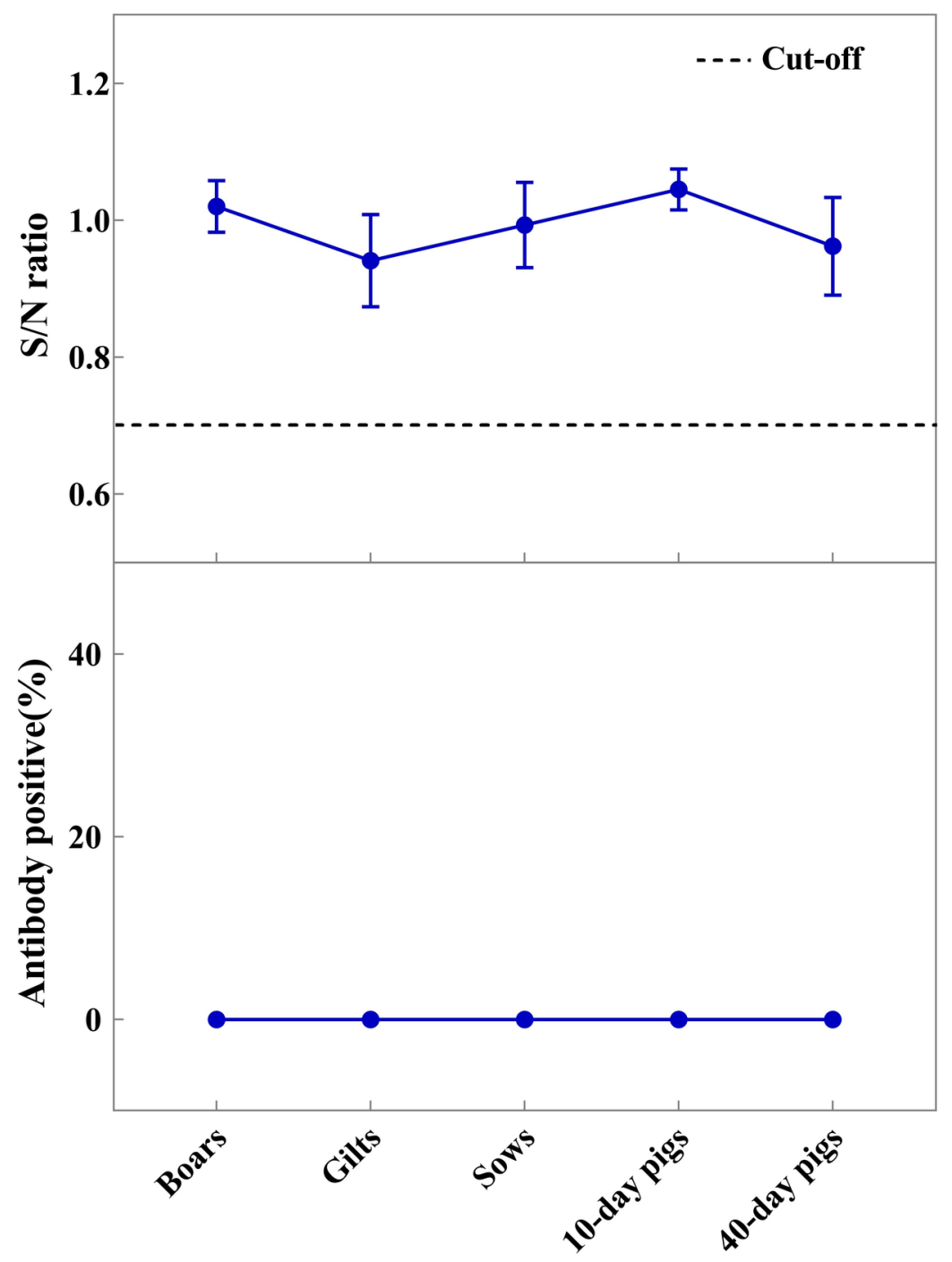

Pig classification 


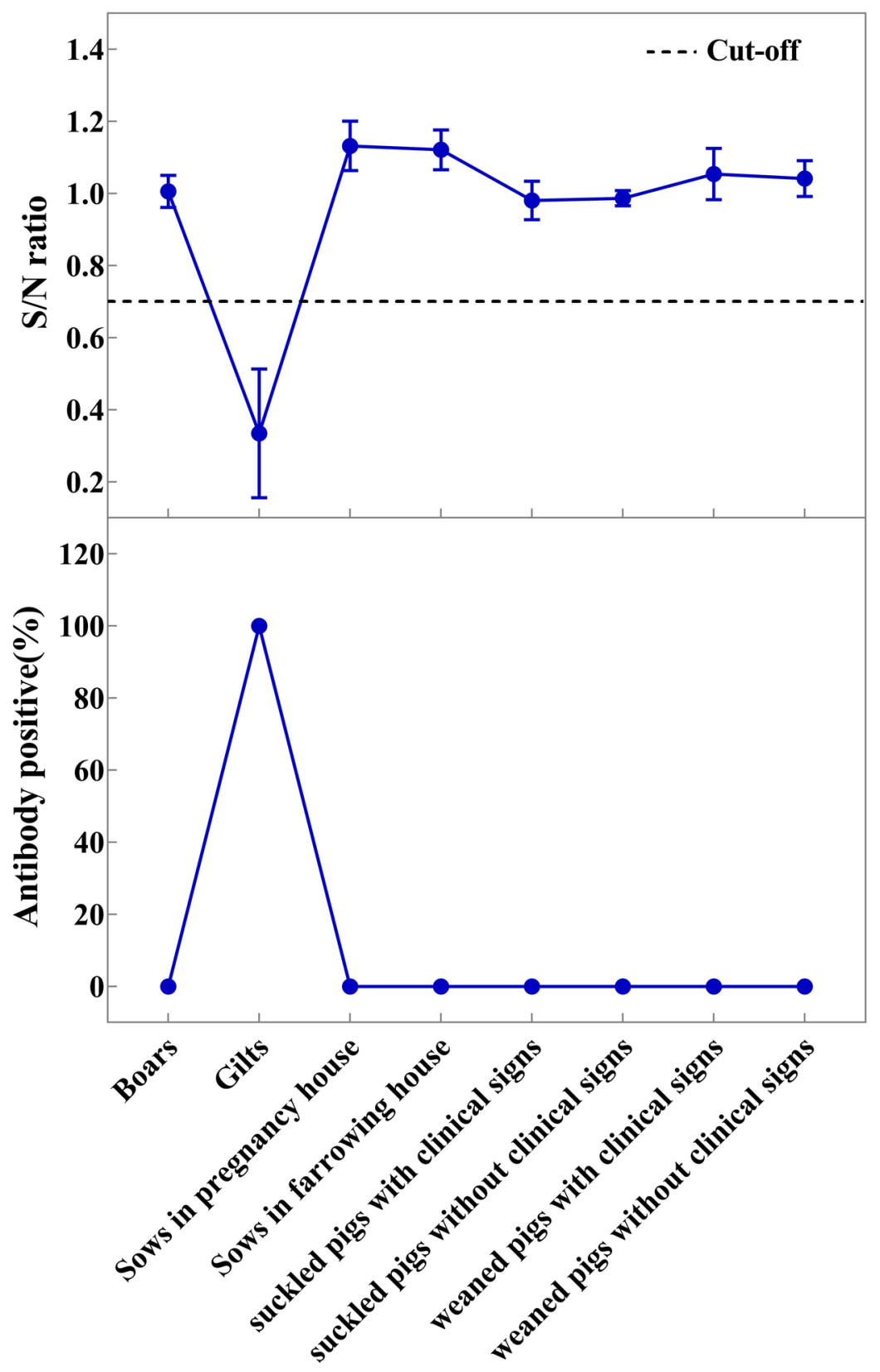

Pig classification 


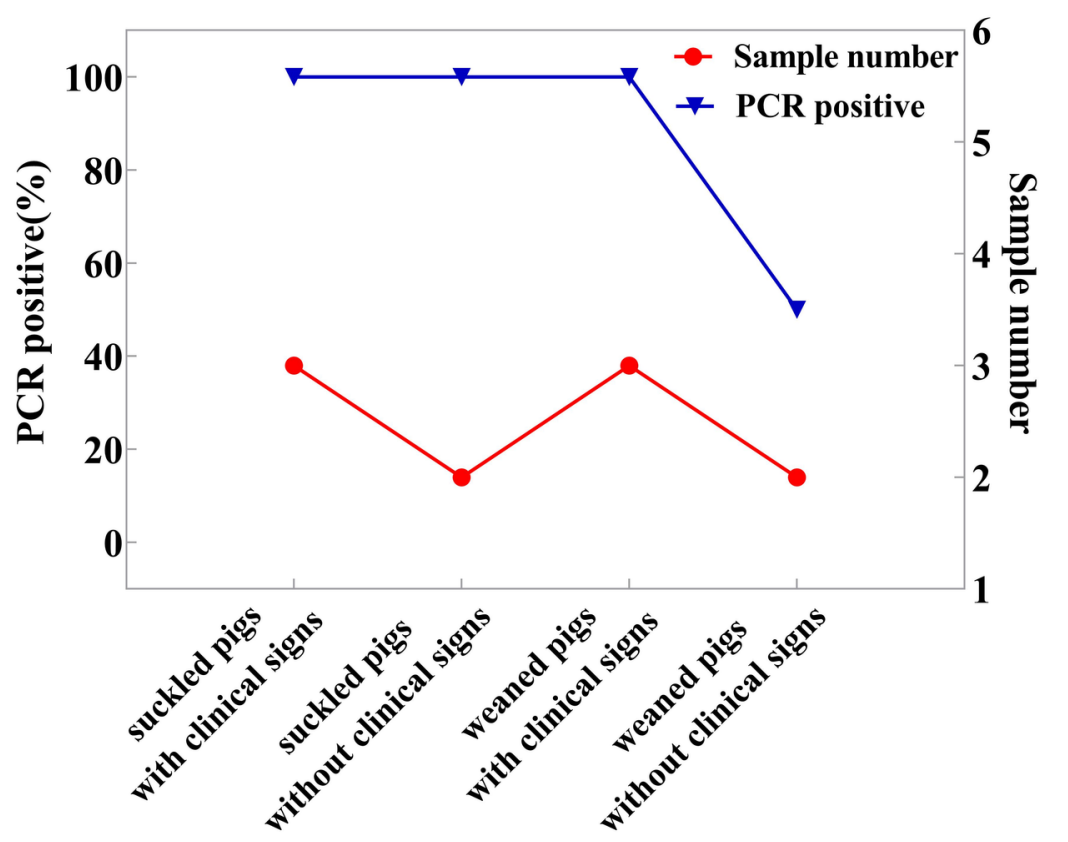

Pig classification 


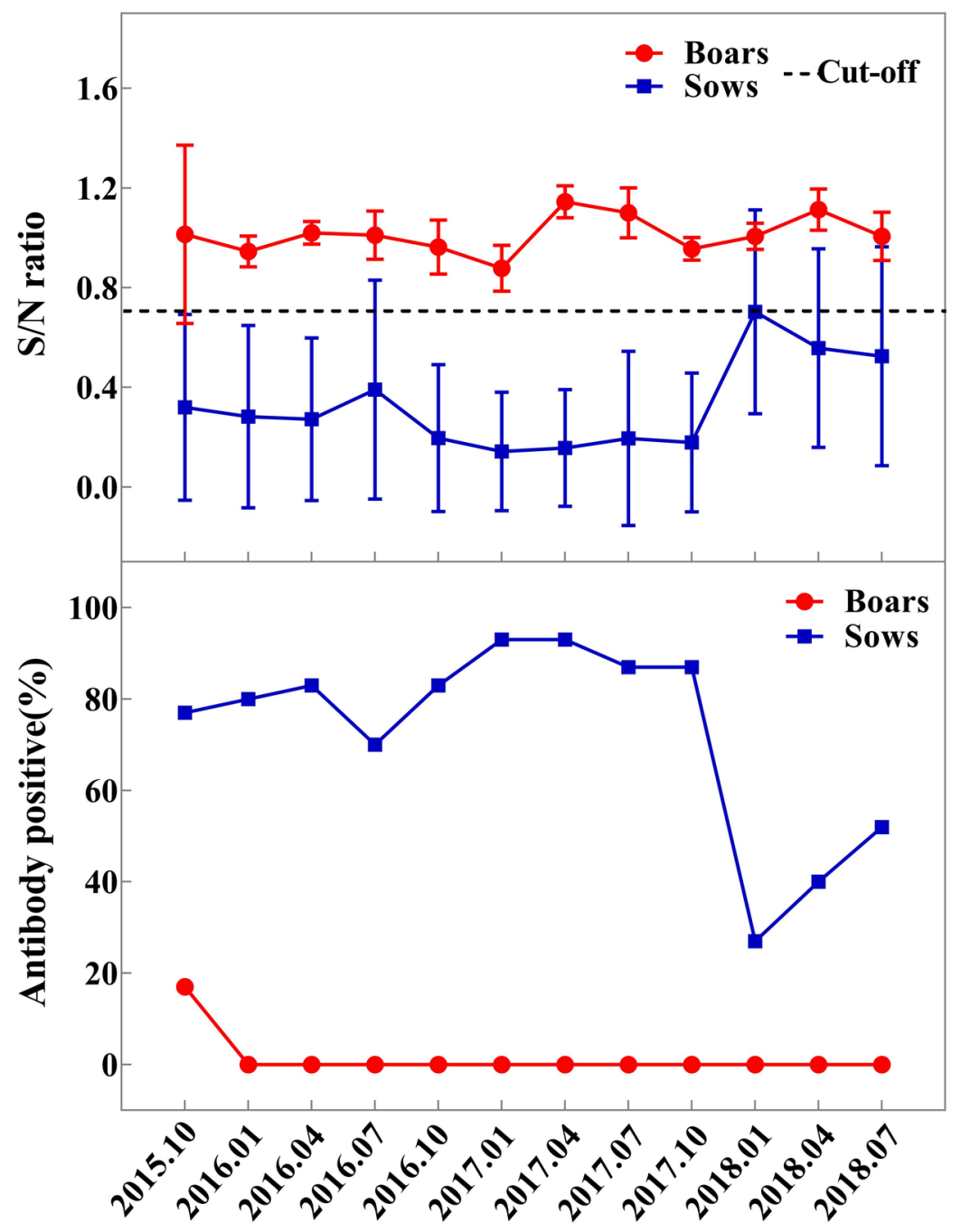

Detection date 


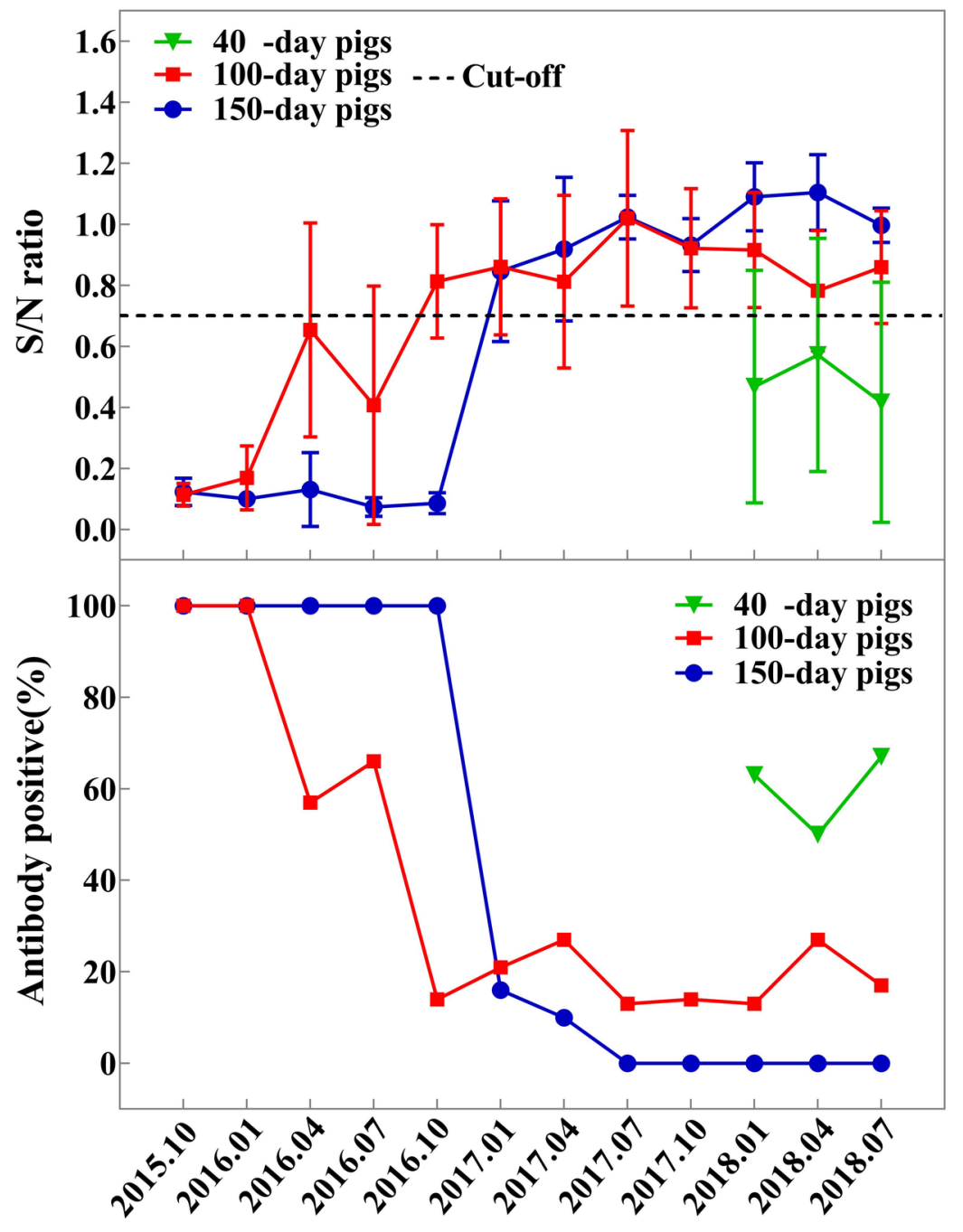

Detection date 